EVS28

KINTEX, Korea, May 3-6, 2015

\title{
EV Motor Controller Target Cooling by Using Micro Thermoelectric Cooler
}

\author{
Frank Kou-Tzeng Lin ${ }^{1}$, Po-Hua Chang ${ }^{2}$, Chih-Yu Hwang ${ }^{3}$, Min-Chuan Wu ${ }^{4}$, Yi-Shin Chen ${ }^{5}$ \\ ${ }^{1}$ Industrial Technology Research Institute (ITRI), Rm. 200, Bldg. 58, 195, Sec. 4, Chung Hsing Rd., Chutung, Hsinchu, \\ Taiwan 310, ROC.FrankKTLin@itri.org.tw \\ ${ }^{5}$ National Taipei University of Technology, Taiwan, ROC.
}

\begin{abstract}
The motor controller is an important component in electric vehicle. Controller always generates heat and needs cooling as electric vehicle driving. Micro thermoelectric cooler ( $\mu$ TEC) with many advantages becomes a potential cooling device for controller recently. This study uses the commercial software ANSYS workbench 14.5 to investigate the influence of the activated number and located position of $\mu$ TEC on controller chip cooling. The following simulation results are obtained: (1) $\mu$ TEC activating may assist cooling between 0 second and 60 seconds. The cooling capability enhancement is pronounced as the number of activated $\mu \mathrm{TEC}$ increased. (2) $\mu \mathrm{TEC}$ activating may not assist cooling between 60 seconds and 156 seconds because the energy on the hot side of $\mu$ TEC is unable to be removed effectively. "All $\mu$ TEC open" method gives the poorest cooling performance in this region.

Keywords: Electric vehicle, Motor controller, Micro thermoelectric cooler, Target cooling.
\end{abstract}

\section{Introduction}

The motor controller is an important component in electric vehicle $(\mathrm{EV})$. Its developing trend is increasing output power and decreasing volume. In general, the controller contains many power electric devices such as IGBT, Diode, and Mosfet as well. During driving process, the power electric devices switch frequently and generate great amount of heat. It not only produces uneven high temperature distribution in power electric devices but also forms local hot spot inside the chip of the controller. As a result, the performance of the controller degrades significantly.
Thermoelectric cooler (TEC) consists of many semiconductor elements. It generates cold face and hot face on both side of TEC as powered by direct current. The cold side of TEC may be used to cool high temperature power electric devices. Micro thermoelectric cooler ( $\mu$ TEC) with the advantages of no moving parts, without noise, long operating life, small size, no refrigerants, and precise temperature control [1,2], it becomes a potential cooling device recently. At present, the researches of TEC on EV application are mostly focusing on the air conditioning system and the heating devices [2]. Among those applications, $\mu$ TEC may be fit into compact size of controller due to its dimension is smaller than that of power element chip. The relevant literatures are described as follows: 
Sullivan et al. [3] used the thin-film thermoelectric cooler (thin film TEC) to carry out the heat dissipation for the chip set of microprocessor through $3 \times 3$ matrix arrangement. It was found when 9 Thin film TEC were activated simultaneously, the maximum temperature reduction of the chip would be $11{ }^{\circ} \mathrm{C}$ within 0.03 seconds, but the temperature rise rapidly thereafter. Chowdhury et al. [4] studied the cooling method for chip local hot spot, and the result revealed that the temperature reduction was $7.6{ }^{\circ} \mathrm{C}$ by passive cooling. If the thin film TEC was also used, the maximum temperature reduction would be $14.9{ }^{\circ} \mathrm{C}$ under the optimal input current of $3 \mathrm{~A}$. Wang et al. [5] used the thin film TEC to do parametric study of IGBT cooling. Several forced convective heat transfer coefficient $(\mathrm{h}=10,000,20,000$, and 30,000 $\left.\mathrm{W} /\left[\mathrm{m}^{2} \mathrm{~K}\right]\right)$ are used. The comparison results between cooling with TEC and without TEC are obtained. Not only the maximum temperature could be reduced, but also the maximum temperature difference of all devices was reduced to approaching zero $\left(\Delta T_{\max }=0.06{ }^{\circ} \mathrm{C}\right)$. Zhang et al. [6] used a three-dimensional thermoelectric model to carry out the simulation and optimization analysis for the hetero-structure thin film TEC - Si/SiGe. The research results revealed that such $\mu$ TEC could reduce the temperature of chip by $4.5^{\circ} \mathrm{C}$ at room temperature and $7{ }^{\circ} \mathrm{C}$ at ambient temperature of $100{ }^{\circ} \mathrm{C}$. Yang et al. [7] added a mini-contact structure in thin film TEC heat dissipation module. The research results revealed that such structure could effectively reduce the heat transferred from the surrounding of hot spot to $\mu \mathrm{TEC}$, so as to reduce the temperature of hot spot significantly.

From the above mentioned literatures, it is known that the $\mu$ TEC is mostly applied to processor chip cooling nowadays. Its characteristics are also suitable for using in the heat dissipation problem of motor controller. But the application in vehicle has its uniqueness. During vehicle driving, the controller needs to deal with different driving patterns and perform different way of control, especially in the case of high power demand, such as climbing and acceleration. The controller chips will generate great amount of heat under these conditions. At this moment, the $\mu$ TEC can remove chip energy and reduce temperature quickly.

In this study, the commercial finite element software ANSYS workbench 14.5 is used to analyze the cooling performance of motor controller assembly with $\mu$ TEC. The effect of the activated number and located position of $\mu \mathrm{TEC}$ on controller chip cooling will be discussed.

\section{Thermoelectric Cooling Principle and Mathematical Model}

\subsection{Thermoelectric Cooling Principle}

The thermoelectric cooling principle is described as follows [8]: If without external magnetic field exist, there will be five effects in the thermoelectric cooling process, those are: Seebeck effect, Peltier effect, Thomson effect, Joule effect, and Fourier effect. As shown in Figure 1, when a direct current is applied to one or more pairs of $n-p$ semiconductor thermoelectric device, the electrons and holes at one side of thermoelectric couple moves from $\mathrm{p}$-type material to n-type material by jumping from low energy level to higher energy level. In this process, the thermal energy is absorbed, so the temperature of cold side is reduced. At the other side of thermoelectric device, the thermal energy is released. This is the Peltier effect. When the temperature difference is appeared on both sides of $p-n$ pairs, a Seebeck voltage will be generated. When a current passes through a thermoelectric device with temperature difference on both sides, an energy exchange will be occurred between the device and the environment due to the Thomson effect. This effect is proportional to the current and temperature gradient. When there is a temperature difference between the hot side and cold side of thermoelectric device, a heat conduction effect will be generated, which is the Fourier effect. When a current passes through a thermoelectric couple, an irreversible Joule heat will also be generated. Considering an ideal thermoelectric cooler, when the heat moves from the cold side to the hot side, the heat at the cold side and the hot side can be represented as:

$$
\begin{aligned}
& Q_{h}=\left(\alpha_{p}-\alpha_{n}\right) I T_{h}-\frac{k A}{L}\left(T_{h}-T_{c}\right)+\frac{L}{2 A} I^{2} \rho_{e} \\
& Q_{c}=\left(\alpha_{p}-\alpha_{n}\right) I T_{c}-\frac{k A}{L}\left(T_{h}-T_{c}\right)-\frac{L}{2 A} I^{2} \rho_{e}
\end{aligned}
$$

Where, $Q_{h}$ and $Q_{c}$ are the energy (W) at the hot side and the cold side, respectively, $\alpha_{n}$ and $\alpha_{p}$ are the Seebeck coefficient $(\mathrm{V} / \mathrm{K})$ of n-type and $\mathrm{p}$ type thermoelectric material, respectively, $k$ is the thermal conductivity $(\mathrm{W} /[\mathrm{mK}])$ of thermoelectric material, $A$ is the area $\left(\mathrm{m}^{2}\right)$ of thermoelectric material, $L$ is the height $(\mathrm{m})$ of thermoelectric 
material, $T_{\mathrm{h}}$ and $T_{c}$ are the temperatures $(\mathrm{K})$ at the hot side and the cold side, respectively, $I$ is the input current (A) of thermoelectric cooler, and $\rho_{e}$ is the resistivity $(\Omega \mathrm{m})$. In the equations (1) and (2), three items at the right hand side of the equations are caused by the Peltier effect, Fourier effect, and Joule effect, respectively.

The performance of TEC can be represented by the thermoelectric figure of merit $Z T$.

$$
Z T=\frac{\alpha^{2}}{\rho_{e} k} T
$$

In equation (3), the parameters influencing $Z T$ are the Seebeck coefficient, thermal conductivity, and resistivity.

The coefficient of performance (COP) for TEC is defined as:

$$
C O P=\frac{Q_{c}}{P_{e}}=\frac{Q_{c}}{Q_{h}-Q_{c}}
$$

Where, $P_{e}$ is the input power (W).

\subsection{ANSYS Thermoelectric Couple Governing Equation}

This study uses the commercial software ANSYS to carry out the simulation analysis with Thermal-Electric module on Workbench 14.5. In the thermoelectric couple governing equation used in that module, the energy equation is:

$\rho C_{p} \frac{\partial T}{\partial t}+\nabla \cdot \vec{q}=\dot{q}$

Where, $\rho$ is the density $\left(\mathrm{kg} / \mathrm{m}^{3}\right), C_{p}$ is the specific heat $(\mathrm{J} /[\mathrm{kgK}]), \quad T$ is the absolute temperature $(\mathrm{K})$. Also, $\vec{q}$ is the heat flux $\left(\mathrm{W} / \mathrm{m}^{2}\right)$, which can be represented by the Seebeck coefficient and the thermal conductivity as $\vec{q}=\alpha T \vec{J}-k \nabla T$, and $\dot{q}$ is the heat generated per unit volume $\left(\mathrm{W} / \mathrm{m}^{3}\right)$. The charge continuity equation can be represented as:

$\nabla \cdot\left(\vec{J}+\frac{\partial \vec{D}}{\partial t}\right)=0$

Where, $\vec{J}$ is the current intensity $\left(\mathrm{A} / \mathrm{m}^{2}\right)$, which can be represented by $\vec{J}=(\vec{E}-\alpha \nabla T) / \rho_{e}, \vec{E}$ is the intensity of electric field $(\mathrm{V} / \mathrm{m})$, and $\vec{D}$ is the intensity of electric flux $\left(\mathrm{C} / \mathrm{m}^{2}\right)$.

When the steady-state analysis is carried out, equations (5) and (6) can be simplified as:

$\nabla \cdot \vec{q}=\dot{q}$

$\nabla \cdot \vec{J}=0$

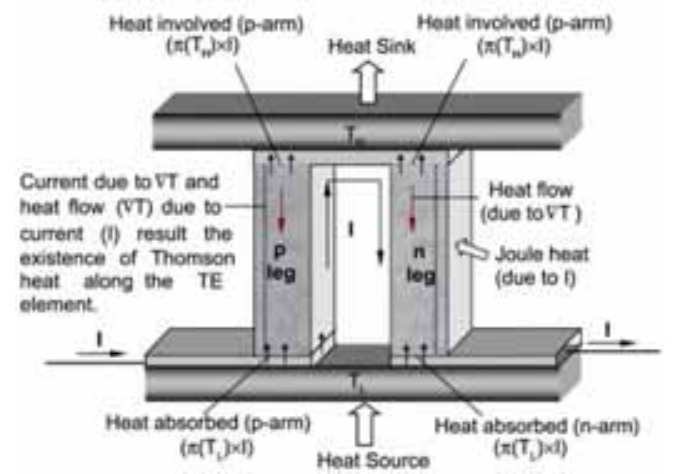

Figure 1: Operation principle of thermoelectric cooler [8]

\section{Finite Element Analysis}

\subsection{Equivalent Model of Micro Thermoelectric Cooler}

In the ANSYS software, a three-dimensional thermoelectric model is created first for the followup simulation analysis. Because of the dimensions of the parts in the model are different widely, the mesh quality always poor by using regular meshing technique. So the equivalent model of $\mu \mathrm{TEC}$ is created for the simulation. Its cooling parameters are derived from the energy balance equation. The equivalent Seebeck coefficient $\alpha_{e q}$, $(\mathrm{V} / \mathrm{K})$, equivalent thermal conductivity $k_{e q}$, $(\mathrm{W} /[\mathrm{mK}])$, and equivalent resistivity $\rho_{e q},(\Omega \mathrm{m})$ can be obtained from the following equations:.

$\alpha_{e q}=2 N \alpha$

$k_{e q}=\frac{2 N k A}{L}$

$\rho_{e q}=\frac{2 N \rho_{e} L}{A}$

Where, $N$ is the number of thermoelectric element pairs. According to the material parameters provided by the manufacturer of thermoelectric device used in this study associated with equation (9) to equation (11), the coefficient of performance for $\mu$ TEC can be obtained as shown in Table 1 . This parameter will be used for device material setting in ANSYS software.

Before conducting the heat transfer simulation, the coefficient of performance (COP) for $\mu$ TEC should be confirmed first. At pre-processing, the hexahedron 20 nodes couple element (SOLID 226) is adopted to set up the mesh. Every part has at least four layers of mesh at thickness direction. Total mesh of the whole equivalent model is 2000 as shown in Figure 2. The corresponding COP of temperature difference at hot side temperature of 
$25{ }^{\circ} \mathrm{C}$ is shown in Figure 3 , and the maximum value is 13.5 .

Table 1: Parameters for equivalent model of micro thermoelectric cooler

\begin{tabular}{|c|c|c|c|}
\hline c & $\begin{array}{l}\text { Seebeck coefficient } \\
\text { (V/K) }\end{array}$ & $\begin{array}{c}\text { Resistivity. } \\
(\Omega \mathrm{m})\end{array}$ & $\begin{array}{l}\text { Thermal conductivity. } \\
\text { (W/[mK] }\end{array}$ \\
\hline $\begin{array}{l}\text { Thermal elements. } \\
\begin{array}{l}\text { (PN)- } \\
\mathrm{L} \times \mathrm{W} \times \mathrm{H}(\mathrm{mm}) \\
=3.6 \times 3.6 \times 0.06 .\end{array}\end{array}$ & 0.085 & 1.512 & 0.463 \\
\hline $\begin{array}{c}\text { Substrate } \\
\left(\mathrm{Al}_{2} \mathrm{O}_{3}\right) \\
\mathrm{L} \times \mathrm{W} \times \mathrm{H}(\mathrm{mm}) \\
=3.6 \times 3.6 \times 0.5\end{array}$ & $\cdots$ & $\cdots$ & 35.3. \\
\hline $\begin{array}{c}\text { Trace } \\
(\mathrm{Cu}) \\
\mathrm{L} \times \mathrm{W} \times \mathrm{H}(\mathrm{mm}) \\
=3.6 \times 3.6 \times 0.27\end{array}$ & - & $1.7212 \times 10^{8}$ & 386. \\
\hline
\end{tabular}

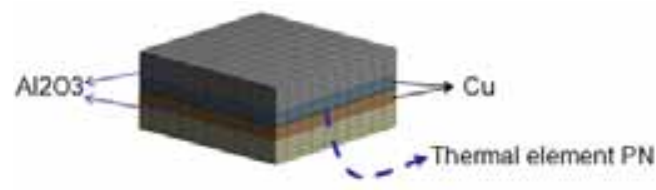

Figure 2: Finite element model of equivalent micro thermoelectric cooler

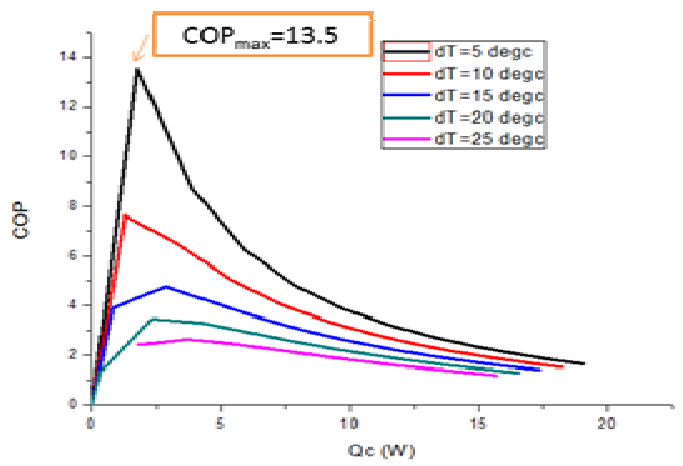

Figure 3: COP of micro thermoelectric cooler (hot side temperature is fixed at $25^{\circ} \mathrm{C}$ )

\subsection{Local Model Analysis of Controller Chip Set}

The real model of motor controller and Mosfet chip local model are shown in Figure 4. The main purpose of this study is to understand the heat transfer behaviour between micro thermoelectric cooler and Mosfet chip set. In order to catch the characteristics of $\mu$ TEC more easily and reduce the simulation time also, the original controller model with 24 heating chips is simplified into a local model with single heating chip (hereinafter called local model). The local model contains the following elements: Mosfet chip, equivalent printed circuit board $\left(\mathrm{PCB}_{\mathrm{eq}}\right)$, aluminum base, and heat sink. A rectangular space in aluminum base right beneath the heating chip is arranged for install $9 \mu$ TEC. The dimension of each $\mu \mathrm{TEC}$ is $3.6 \mathrm{~mm}$ width, $3.6 \mathrm{~mm}$ length, and $0.06 \mathrm{~mm}$ height. The space between two $\mu \mathrm{TEC}$ is $0.5 \mathrm{~mm}$.

The computational mesh of the local model is designed according to the following method: hexahedral 20 nodes - SOLID 90 type mesh is used in heating chip, hexahedral 20 nodes couple element - SOLID 226 type mesh is used in $\mu$ TEC, and tetrahedral 10 nodes hot element - SOLID 87 type mesh is used for other components. Total number of mesh is 68,115 . The whole finite element model is shown in Figure 5, and the detailed parameters are shown in Table 2.

This study adopts the transient analysis. The total analysis time is 156 seconds. In order to simulate the driving condition of the vehicle, the ambient temperature is keeping at $40{ }^{\circ} \mathrm{C}$, the convective heat transfer coefficient on the boundary is setting at $5 \mathrm{~W} /\left[\mathrm{m}^{2} \mathrm{~K}\right]$, the heating power of the chip is setting at $8.333 \mathrm{~W}$, and the heating time of the chip is arranged between 1.1 seconds and 156 seconds. The maximum input current of $\mu \mathrm{TEC}$ is $0.5 \mathrm{~A}$ at 1.1 seconds from the beginning of the simulation time, then the current value drops gradually in linear way subsequently. When the time reaches 156 seconds, the current is the lowest value of 0.1 A. In order to investigate the optimal number of activating $\mu \mathrm{TEC}$, eight different activating methods are designed as shown in Fig. 6. Those are: (1) $9 \mu \mathrm{TEC}$ are all deactivated, indicated by "Open 0", (2) center $\mu$ TEC activated and 8 other $\mu$ TEC are all deactivated, indicated by "Open 1", (3) $4 \mu \mathrm{TEC}$ near center one activated and 5 other $\mu$ TEC are all deactivated, indicated by "Open 4 Inside", (4) $4 \mu \mathrm{TEC}$ near outer corner activated and 5 other $\mu$ TEC are all deactivated, indicated by "Open 4 Outside", (5) $5 \mu$ TEC near center and include that one activated and 4 other $\mu$ TEC are all deactivated, indicated by "Open 5 Inside", (6) 5 $\mu \mathrm{TEC}$ at center and outer corner activated and 4 other $\mu$ TEC are all deactivated, indicated by "Open 5 Outside", (7) $8 \mu$ TEC exclude center one activated and center one deactivated, indicated by "Open 8", and (8) $9 \mu$ TEC are all activated, indicated by "Open 9".

The U, V, and $\mathrm{W}$ alternating output power with different arms arrangement in associate with $3 \mathrm{D}$ heat source and heat sink geometry in EV application may produce uneven or hot spot temperature distribution on controller. The function of the above eight activating methods on chip cooling serves as target cooling of $\mathrm{EV}$ controller. 


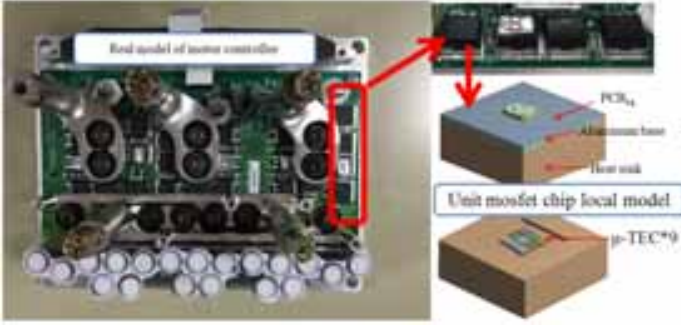

Figure 4: Motor controller and local model

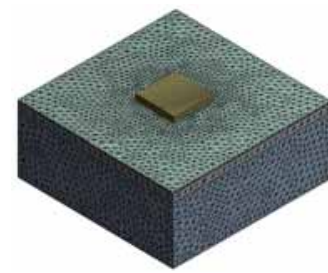

(a) FEA model

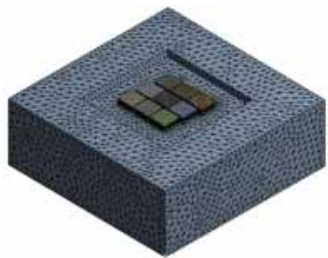

(b) $\mu \mathrm{TEC}$ location Figure 5: Computational mesh of local model

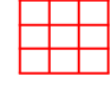

Open 0

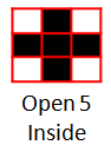

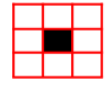

Open 1

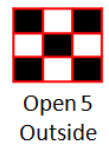

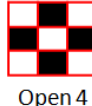

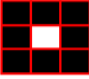

Open 8

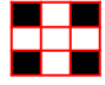

Open 4 Outside

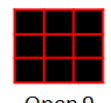

Open 9
Figure 6: Activating methods of micro thermoelectric cooler

Table 2: Thermal parameters of local model

\begin{tabular}{|c|c|c|c|}
\hline & $\begin{array}{c}\text { Density } \\
\left(\mathrm{kg} / \mathrm{m}^{2}\right)\end{array}$ & $\begin{array}{c}\text { Specific heat- } \\
(\mathrm{J} / \mathrm{kgKN})\end{array}$ & $\begin{array}{c}\text { Thermal conductivity- } \\
(\mathrm{W} / \mathrm{mK}]\end{array}$ \\
\hline $\begin{array}{c}\mathrm{PCB} \\
\mathrm{L} \times \mathrm{W} \times \mathrm{H}(\mathrm{mm}) \\
=40 \times 40 \times 0.4\end{array}$ & 1600 & 4 & 850 \\
\hline $\begin{array}{c}\text { Alumina base } \\
\mathrm{L} \times \mathrm{W} \times \mathrm{H}(\mathrm{mm}) \\
-40 \times 40 \times 2\end{array}$ & 2689 & 237.5 & 951 \\
\hline $\begin{array}{c}\text { Heat } \operatorname{sink} \\
\mathrm{L} \times \mathrm{WW} \times \mathrm{H}(\mathrm{mm}) \\
-40 \times 40 \times 14.6\end{array}$ & 2689. & 237.5 & 951 \\
\hline $\begin{array}{c}\mathrm{Chip} \\
\mathrm{L} \times \mathrm{W} \times \mathrm{H}(\mathrm{mm}) \\
=10 \times 10 \times 1.6\end{array}$ & 8920 & 386 & 385 \\
\hline
\end{tabular}

\section{Results and Discussions}

The analysis is conducted in a transient condition and results are shown in Figure 7. Figure 7(a) shows the temperature distributions of the controller chip versus time under eight activating methods. Total simulation time is 156 seconds. It is noticed that eight temperature curves merge at a cross point near 40 seconds. Enlarge view of the results between 0 and 60 second is shown in Figure 7(b) for easily reading purpose.
The temperature distributions can be divided into two regions. First region is located between 0 second and 60 seconds, second region is located between 60 seconds and 156 seconds. In the first region, chip temperatures are maintained at constant value of $40{ }^{\circ} \mathrm{C}$ from 0 second to 1.1 seconds, those curves vary significantly from 1.1 seconds to 4.4037 seconds. Chip temperature on first activating method "Open 0 " increases from 40 ${ }^{\circ} \mathrm{C}$ to $50.414{ }^{\circ} \mathrm{C}$ sharply, the temperature increases with low constant slope hereafter. Chip temperature on second activating method "Open 1" increases from $40{ }^{\circ} \mathrm{C}$ to $47.632{ }^{\circ} \mathrm{C}$ sharply, and then increases with a constant slope little higher than that of the curve "Open 0" hereafter. Chip temperature on forth activating method "Open 4 Outside" increases sharply first then decreases to $43.47^{\circ} \mathrm{C}$, and then increases with a constant slope little higher than that of the curve "Open 1" hereafter. Chip temperature on third activating method "Open 4 Inside" increases sharply first then decreases to $42.149{ }^{\circ} \mathrm{C}$, and then increases with a constant slope little higher than that of the curve "Open 4 Outside" hereafter. Chip temperature on sixth activating method "Open 5 Outside" increases sharply first then decreases to $41.022^{\circ} \mathrm{C}$, and then increases with a constant slope little higher than that of the curve "Open 4 Inside" hereafter. Chip temperature on fifth activating method "Open 5 Inside" increases sharply first then decreases to $39.721{ }^{\circ} \mathrm{C}$, and then increases with a constant slope little higher than that of the curve "Open 5 Outside" hereafter. Chip temperature on seventh activating method "Open 8 " increases sharply first then decreases to 35.798 ${ }^{\circ} \mathrm{C}$, and then increases with a constant slope little higher than that of the curve "Open 5 Inside" hereafter. Chip temperature on eighth activating method "Open 9" increases sharply first then decreases to $33.652{ }^{\circ} \mathrm{C}$, and then increases with a constant slope little higher than that of the curve "Open 8" hereafter.

Roughly speaking, the controller cooling performance may be divided into the following two conditions:

First condition: $\mu$ TEC may assist cooling on first region between 0 second and 60 seconds. The cooling capability enhancement is pronounced as the number of activated $\mu$ TEC increased. In this region, the poorest cooling performance for "Open 0 " method may be observed due to the highest temperature among eight methods. It is reasonable because there is no TEC assist cooling adopted in such design. On the other way, the best cooling 
performance for "Open 9" method may be observed due to the lowest temperature among eight methods. It is acceptable because all TEC are activated to assist cooling in such design. Second condition: $\mu$ TEC may not assist cooling on second region between 60 seconds and 156 seconds. In this region, the poorest cooling performance for "Open 9" method may be observed due to the highest temperature among eight methods. On the other way, the best cooling performance for "Open 0" method may be observed due to the lowest temperature among eight methods. The reason why $\mu$ TEC may not assist cooling in this region is because the energy on the hot side of $\mu$ TEC is unable to be removed effectively. Such energy will accumulate on the heat sink and bring back to the controller chip to induce reheating phenomena and increase chip temperature as well when the activation time exceeds a certain range. In present study, the margin of the exceeding time is around 60 seconds. This poor heat dissipation effect is required to be improved. The first feasible method is to extend the effective thermoelectric cooling time of $\mu \mathrm{TEC}$, and the second feasible method is to propose a fast way of heat removing method from hot side of $\mu$ TEC.

The detail data are shown in Table 3. First column shows seven $\mu$ TEC activating methods. Second column shows the time of sharp temperature change ending. Third column shows chip temperature at the time shown in second column. Forth column shows chip temperature without activated $\mu$ TEC. And fifth column shows temperature difference. It is noticed from the table that the temperature of the controller chip is keeping at maximum value of $50.414{ }^{\circ} \mathrm{C}$ when nine $\mu$ TEC are all closed. In this case, the chip always maintain at maximum temperature without external cooling device assistant. As $\mu$ TEC open and activates, the temperature of controller power element reduces effectively in short period of time. In the table, temperature difference is defined as the deviation between the temperature of the chip as $\mu$ TEC is closed and the temperature of the chip as $\mu$ TEC is open. When one $\mu$ TEC is open as apply "Open 0" method, the external assisting cooling power is the least amount, and the minimum temperature difference is obtained. As the number of activating $\mu \mathrm{TEC}$ increases, the temperature difference increases too. For example, temperature difference equals $6.944{ }^{\circ} \mathrm{C}$ as four outside $\mu \mathrm{TEC}$ are all open, temperature difference equals $10.693{ }^{\circ} \mathrm{C}$ as five inside $\mu$ TEC are all open, and temperature difference equals $16.762{ }^{\circ} \mathrm{C}$ as nine $\mu$ TEC are all open. It is seen from the table that the application of $\mu$ TEC can reduce the temperature of controller actually. According to the data in table 3 , the position of the $\mu$ TEC will influence the $\mu$ TEC cooling capability obviously. For instance, compare the temperature difference of the following two cases: $\ulcorner 4$ inside $\mu$ TEC open $\lrcorner$ and $\ulcorner 4$ outside $\mu$ TEC open $\lrcorner$, temperature difference equals $8.265^{\circ} \mathrm{C}$ for case $\ulcorner 4$ inside $\mu$ TEC open $\lrcorner$ and temperature difference equals $6.944{ }^{\circ} \mathrm{C}$ for case $\ulcorner 4$ outside $\mu$ TEC open $\lrcorner$. With the same amount of activating $\mu \mathrm{TEC}$, temperature difference for case of $\mu$ TEC located at outside position is $1.321{ }^{\circ} \mathrm{C}$ smaller than that of $\mu$ TEC located at inside position. One reason why different position of $\mu$ TEC reveals different temperature difference is because of the different heat transfer characteristics appears on different conduction path. The other reason is the setting of the chip power source is defined as the total power of the chip volume. The energy of the power element is coming from the center of the chip and then conducted to the exterior boundary of the element. When $\mu$ TEC is located near the center area of the chip, it shows better cooling performance. The same result may be obtained for the following two cases: $\ulcorner 5$ inside $\mu$ TEC open $\lrcorner$ and $\ulcorner 5$ outside $\mu$ TEC open $\lrcorner$. The optimum design of EV motor controller cooling by using $\mu$ TEC may be obtained by conducting the following further analysis: (1) different size (include width, length, and height) of $\mu$ TEC. (2) different number of $\mu$ TEC. (3) different $\mu$ TEC located position with respect to chip.

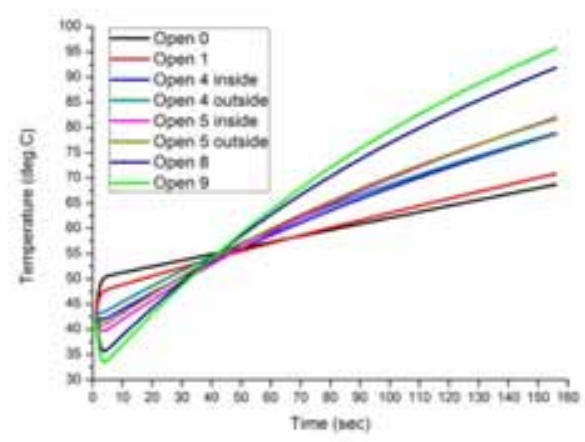

(a) $0 \sim 156 \mathrm{~s}$ 


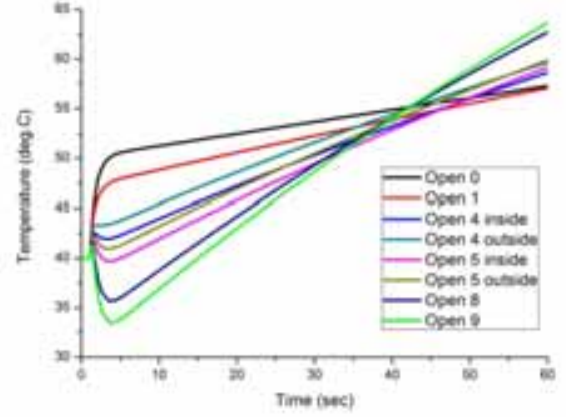

(b) $0 \sim 60 \mathrm{~s}$

Figure 7: Transient analysis results of local model

Table 3: Occur time and temperature of maximum temperature difference

\begin{tabular}{|c|c|c|c|c|}
\hline & Time (sec) & $\begin{array}{c}\text { Temperature } \\
\text { (C) }\end{array}$ & $\begin{array}{l}\text { Temperature of } \\
\text { Open O (c) }\end{array}$ & $\begin{array}{l}\text { Temperature } \\
\text { difference (C) }\end{array}$ \\
\hline Open 1 . & 4,40372 & 47.632 & 50.414 & 2.782 \\
\hline $\begin{array}{l}\text { Open } 4 \\
2 \text {-inside }\end{array}$ & 4,4037 & 42.149 & 50.414 & 8.265 \\
\hline Open 4 & 4.4037 & 43.47 & 50.414 & 6.944 \\
\hline $\begin{array}{l}\text { Open } 5 \\
\mathbf{F}_{\text {inside }}\end{array}$ & 4.4037 & 39.7212 & 50.414 & 10.693 \\
\hline $\begin{array}{l}\text { Open } 5 \\
\text { Woutside }\end{array}$ & 4.4037 & 41.022 & 50.414 & 9.392 \\
\hline Open $8=$ & $4,4037$. & 35.798 & 50.414 & 14.616 \\
\hline Open 9 미 & $4.4037 \mathrm{r}$ & 33.652 & 50.414 & 16.762 \\
\hline
\end{tabular}

\section{Conclusions}

The application of $\mu \mathrm{TEC}$ on EV motor controller chip cooling has been analysed in this study by using a simplified local model of the controller. According to the simulation results, the following conclusions are obtained:

(1) $\mu$ TEC may assist cooling between 0 second and 60 seconds. The cooling capability enhancement is pronounced as the number of activated $\mu$ TEC increased. Temperature difference between " $0 \mu$ TEC open" and "1 $\mu$ TEC open" is $2.782{ }^{\circ} \mathrm{C}$, and temperature difference between " $0 \mu$ TEC open" and "All $\mu$ TEC open" is $16.762^{\circ} \mathrm{C}$.

(2) $\mu \mathrm{TEC}$ may not assist cooling between 60 seconds and 156 seconds because the energy on the hot side of $\mu$ TEC is unable to be removed effectively. "All $\mu$ TEC open" method gives the poorest cooling performance in this region.

\section{Acknowledgments}

Authors would like to thank the research budget supported from Ministry of Economic Affairs, ROC (ITRI project no. FY103: D301ARY340). And comment on thermal parameters calculation of local model from Electronics and Optoelectronics Research Laboratories, ITRI is appreciated.

\section{References}

[1] S. Daly, Automotive air conditioning and climate control systems, ISBN: 978-0-7506-6955-9, Amsterdam, Boston: Elsevier Butterworh Heinemann, 2006.

[2] Z. Qi, "Advances on air conditioning and heat pump system in electric vehicles - A review," Renewable and Sustainable Energy Reviews, Vol. 38, pp. 754-764, 2014.

[3] O. Sullivan, M. P. Gupta, S. Mukhopadhyay, and S. Kumar, "Array of thermoelectric coolers for onchip thermal management," Journal of Electronic Packaging, Vol. 134, 2012.

[4] I. Chowdhury, R. Prasher, K. Lofgreen, G. Chrysler, S. Narasimhan, R. Mahajan, D. Koester, R. Alley, and R. Venkatasubramanian, "On-chip cooling by superlattice-based thin-film thermoelectrics," National Nanotechnology, Vol. 4, 2009.

[5] P. Wang, P. McCluskey, and A. Bar-Cohen, "Hybrid solid- and liquid-cooling solution for isothermalization of insulated gate bipolar transistor power electronic devices," IEEE Transactions Components, Packaging and Manufacturing Technology, Vol. 3, No. 4, pp. 601-611, 2013.

[6] Y. Zhang, D. Vashaee, J. Christofferson, A. Shakouri, G. Zeng, C. LaBounty, and J. Piprek, "3D electrothermal simulation of heterostructure thin film micro-coolers", ASME-2003-42767, 2003.

[7] B. Yang, P. Wang, and A. Bar-Cohen, "Thermoelectric mini-contact cooler for hot-spot removal in high power devices," Electronic Components and Technology Conference, pp. 9971002, 2006.

[8] A. Chakraborty, B. B. Saha, S.Koyama, and K. C. $\mathrm{Ng}$, "Thermodynamic modelling of a solid state thermoelectric cooling device: Temperatureentropy analysis", Internal Journal of Heat and Mass Transfer, Vol. 49, pp. 3547-3554, 2006.

[9] E. E. Antonova and D. C. Looman, "Finite elements for thermoelectric device analysis in 
ANSYS, International Conference on Thermoelectric, Proceedings V, pp. 200-203, 2005 .

[10] H. Y. Zhang, Y. C. Mui, and M. Tarin, "Analysis of thermoelectric cooler performance for high power electronic packages, Applied Thermal Engineering," Vol.30, pp. 561-568, 2010 .

\section{Authors}

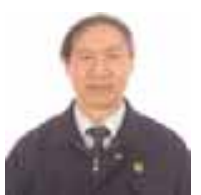

Frank Kou-Tzeng Lin was born in Taiwan, ROC in 1950. He received the Ph.D. degree in power machinery engineering from Tsing Hua University, Hsinchu, Taiwan in 2001. Since 1979, he has been an Associate Engineer, Engineer, and Principal Engineer in ITRI. His research interests include thermal management of fluid machinery and electric vehicle.

Roger Po-Hua Chang was born in Taiwan, ROC in 1988. He received the Master degree in power machinery engineering from Tsing Hua University, Hsinchu, Taiwan in 2012. Since 2013, he has been an Associate Researcher in ITRI. His research interests include thermal management of fluid machinery and electric vehicle.

Chih-Yu Hwang was born in Taiwan, ROC in 1987. He received the master degree in mechanical engineering from National Taiwan University, Taipei, Taiwan in 2012.

Since 2012, he has been an Associate Engineer, in ITRI. His research interests include thermal management of fluid machinery and electric vehicle.

Min-Chuan Wu received the B.S. and M.S degrees in Mechanical Engineering from National Chiao Tung University, Taiwan, ROC in 2003 and 2005, respectively. Since 2005, he has been an Associate Researcher in ITRI, Hsinchu, Taiwan. His research interests are mechanical design and patent analysis.

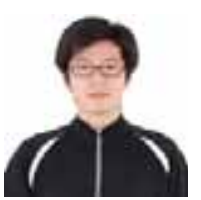

Yi-Shin Chen was born in Taiwan, ROC in 1984 . He is currently a Ph.D. candidate in vehicle engineering department from National Taipei University of Technology, Taiwan. His research topics include structure optimum design of EV, battery pack design of $\mathrm{EV}$, and thermal behaviour

analysis of $\mathrm{LiFePO}_{4}$ battery.

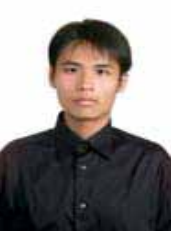

